\title{
Effects of the Gamification Supported Flipped Classroom Model on the Attitudes and Opinions Regarding Game-Coding Education
}

\author{
https://doi.org/10.3991/ijet.v13i01.7634 \\ Hasan Hüseyin Özer ${ }^{\bowtie}$, Sezer Kanbul, Fezile Ozdamli \\ Near East University, Nicosia, North Cyprus \\ hasanhuseyin.ozer@neu.edu.tr
}

\begin{abstract}
The aim of this study is to determine the opinions of teacher candidate students regarding the application and their attitudes towards coding by conducting a Project Development course with the gamification supported flipped classroom approach during the coding period. Quantitative and qualitative methods were used together in this study, which aims to determine the attitudes and opinions of students regarding coding in a gamification supported flipped classrooms over a period of 14 weeks. In the qualitative dimension of the study, pre-test and post-test were applied as attitude measures to assess the students' attitudes towards coding. Furthermore, in the quantitative dimension, semi-structured interview forms and interviews were held in order to obtain more in-depth information. This study was conducted with 35 classroom students who were taking the Project Development course in Computer and Instruction Technology Teaching Departments at Near East University, of whom 3 were female and 32 were male. The results show that the vast majority of teacher candidates were satisfied with the activities implemented through the gamification supported flipped classroom and there were all increases in their motivation and in-class competition.
\end{abstract}

Keywords-gamification, flipped classroom, game, coding, attitudes

\section{Introduction}

In addition to the development of technology, there have been significant changes in many fields, with new trends observed in education in particular. The most significant difference this development has caused is related to students' learning models in schools. As learning approaches are traditionally teacher-centered, they prevent the new trends and approaches being incorporated in education. As the main source of changes in learning approaches in education, the technology is now being used in education due to its simplicity and the availability of materials during the learning phase [1-24-28]. Furthermore, in terms of the needs that have arisen as a result of technological development, such as media literacy, information literacy and technology literacy, it is necessary for students to use and follow the new trends in technology in order to meet these needs [3-5]. Current studies have shown that the teaching of 
coding is necessary so that the students will be able to acquire the required skills [1617-26]. Coding teaching has emerged through visual program languages such as Alice code, code.org and Scratch [19]. Before receiving coding training, students must receive algorithm training, which is inescapable because not only are the code or language to be used important, but the students must also formulate the basic steps of the program as well devise an appropriate flow diagram. Computer coding or coding training are also used for improving students' cognitive thinking abilities. For this reason, it is estimated that these problems can be resolved by using gamified and flipped classroom teaching methods during game development lessons.

Although some have only recently encountered technology, the younger generations are generally considered as "digital natives" [22], who spend the majority of their time playing games on their computers, smart phones or tablets on a daily basis. There has been a rapid increase in game playing frequency, as children and young people exhibit and increasing interest in games, with the improved access and portability of their smartphones and other devices [11]. Hence, in many studies, it has been demonstrated that using this potential can be highly beneficial for learners.

As the main source of changes in learning approaches in education, the technology is now increasingly used education thanks to its simplicity and materials during the learning phase [24-28]. For this reason, instead of the repetitive nature of traditional learning media, there is now a tendency to integrate the technology into education by placing the students in more entertaining, effective and creative situations, this creating solutions for the problems they experience during learning. Among these methods, the flipped classroom and gamification approach present the information both in an open and entertaining manner. Even though the flipped classroom and gamification are different applications, they are perceived as complementary. Gamification has been popular for some time and was first mentioned as a concept in 2002 by Nick Pelling [20]. The flipped classroom approach supported by the gamification is different from the traditional classrooms in terms of its objectives, which include creating a competitive environment where students are entertained, and their interests and motivation levels are elevated.

In a study by Dicheva, Dichev, Agre and Angelova [9], 34 studies about the use of gamification in education were analyzed and the use of gamification in education was interpreted to be positive. This study also showed that gamification has a positive effect on children in terms of improved lesson participation and lesson success; moreover, there has been an increase in the number of students who achieve higher grades in their lessons. Gamification applications were shown to have a positive effect on success which, as demonstrated in the study by Dadakhodjaeva [7].

However, the flipped classroom teaching method uses the existing classroom or community combinations in distance learning systems. There are many systems that can be used in Flipped Classroom Education. In order to realize more effective student learning in virtual classes, there are various plug-ins that can be used in the content management system [12]. Compared to the classical methods of teaching, the Flipped Classroom Teaching approach includes many methods where the students participate in lessons in virtual classrooms [4]. As a result of the online method, inno- 
vative options are available including positive feedback for students, presentation of beneficial videos, online courses and text reading [26].

In a study by Roach [23], training was given to students once a week prior to attending the lesson through video presentation. The videos were uploaded to the system before the lesson and the students were asked to follow the video and learn the material. As a result of this implementation, $76 \%$ of the students gave positive opinions.

The flipped classroom teaching methods encourages the students to watch the videos in their own time and forms the concept of "lesson at home, homework at school". This concept model not only provides lessons in the classroom similar to traditional teaching methods, but also through virtual media in the home environment. After the students have completed these virtual classes at home, they can then come to classroom only for reinforcement so that the students can benefit from the application's instructive consultation features [8]. As mentioned before, coding skills now have significant importance; therefore, the creation of gamification supported flipped classroom teaching media has gained more importance with the aim of making coding lessons more entertaining. Although studies about gamification in education and flipped classroom teaching exist in the literature, there have been no studies that have analyzed both approaches. In this regard, the aim of this study is to determine the opinions of teacher candidate students regarding the applications and the effect on their attitudes towards coding by implementing a Project Development course with gamification supported flipped classroom during a coding period.

\section{Methods}

Quantitative and qualitative methods were used together in this study, which aims to determine the attitudes and opinions of students regarding coding in gamification supported flipped classrooms for a period of 14 weeks. In the qualitative dimension of the study, pre-test and post-test were applied as the attitude measure for students towards coding. However, in the quantitative dimension, semi-constructed interview forms and interviews were conducted in order to obtain more in-depth information. While the qualitative and quantitative methods can be used separately, they can also be used together in educational studies so that the findings can support each other. Muijs [21] mentioned that the use of qualitative and quantitative methods together is the most beneficial research method. The research design is presented in Figure 1.

\subsection{Participants}

This study was conducted with 35 classroom students who were taking the Project Development course in the Computer and Instruction Technology Teaching Departments at Near East University of whom 3 were female and 32 were male. The gender distribution was normal and as the average age was calculated as 21 . 


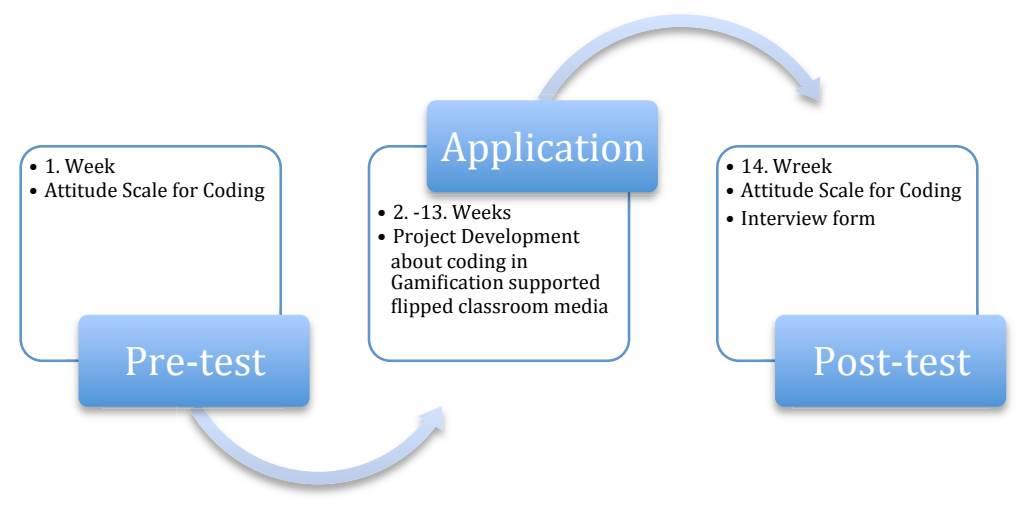

Fig. 1. Research design

\subsection{Participants}

The data gathering tools were applied in order to determine the opinions of the students about the application and the effect on their attitudes towards coding in the gamification supported flipped classroom model through gamification activities, which are explained as following:

Attitude Scale about Coding Learning. As improved by Keçeci, Alan and Zengin [17], the "Attitudes for Coding Teaching" Scale was used for determining the attitudes of students about coding. The scale was developed based on the concerns about the anti-social elements of computers, the interest related to the use of computer games in education and their desires. The scale includes a total of 28 statements, including 22 positive and 6 negative statements. There are 12 items in the first factor, 11 items in the second and 5 items in the third factor. When the data of the third factor entry was done, it was then done in reverse. Furthermore, while the Cronbach's alpha reliability coefficient of the scale was calculated as .833 in their studies, in this study it was calculated as .889 .

Interview Form. In order to determine the teacher candidate students' opinions about project development training through the gamification supported flipped classroom approach, an interview form was used which was created after obtaining expert views by the researchers. The determination of perspectives of the participant teacher candidate students were obtained through the interview forms. The interviews held at the end of each 14-week application lasted approximately 15-20 minutes. The semistructured interview form includes four questions, including: "How did you feel at the beginning of the semester when you heard that a different application was going to be used?", "As computer and instructional technologies are the teachers of the future, how do you evaluate the videos on the environment that is designed for flipped classroom model?", "What kind of difficulties did you face within the process?" and lastly "As you have won badges for your participation in the in-class activities and for the accomplishment of tasks in the gamification applications, in your opinion; what kind of advantages and limitations does this application have?" 


\subsection{Data Analysis}

For the data analysis aspect of the research, statistical analysis techniques such as percentage, mean, standard deviation and paired samples were used. The values obtained as a result of the analysis were interpreted with a 0.05 significance level. During the qualitative data analysis, the interviews that had been audio-recorded recorder were digitally transcribed by one of the researchers, while the other two researchers double-checked the data. After this phase, the data were analyzed using the in-depth content analysis technique. In addition to this, the obtained qualitative data were supported by making direct quotations from the candidate teacher students' opinions. The names of the candidate teachers have not been revealed and they were mentioned only as teacher candidates (TC).

\subsection{Application}

In terms of the online environment, Moodle was the preferred distance learning environment used at the university. The prepared videos for the lesson were uploaded to YouTube and then integrated to Moodle. According to the cognitive learning theory, video is an effective tool formed by collating the visual and audio elements effectively during learning. However, the cognitive load only occurs when a transfer is attempted to be done that exceeds the human brain working capacity [30]. For this reason, 8-12 minute interactive videos were prepared for all topics via Captivate. By adding multiple choice questions at different periods during the videos, the students were required to watch the complete video. The badges feature was added as a plug-in on the Moodle system by the researcher. Additionally, the researchers prepared quizzes every week using the Kahoot application for the in-class activity.

In the first week of the 14-week application, the gamification supported flipped classroom model was introduced to the students, the tasks were explained to them and the attitude scale was applied as a pre-test. The teacher candidate students formed cooperative groups with 3 or 4 people. The goal of the cooperative learning groups was to complete the educational game improvement projects by the end of the semester, which was one of requirements of Project Development course, and then the students were required to implement a trial on the target audience.

When the students developed educational games, they used software such as Java, Scratch, Flash, Captivate, Camtasia, Vizia, EDpuzzle, etc. which they had learnt during their 4 year study program. The teacher candidates answered the questions after watching the videos before the lesson during the semester and they searched and learned from the required documents. They were able to solve the parts that they did not understand by asking for assistance from their friends or teachers online. When they could not solve a problem, they could learn as a result of the discussions that were conducted in the classroom. Within the scope of the in-class activities, active project development of the cooperative learning groups was provided. By organizing various weekly activities, the aim was to motivate and attract the interest of the teacher candidates. Solutions to the difficulties that were faced by the teacher candidates during coding and design were produced through the brainstorming technique in 
some of the lessons. In some of the lessons, experts in the field were invited to present their views on the education game software that they had developed (See Figure 2).

In the last week of the implementation, the teacher candidates allowed the target audience to play the educational games they had developed, so that any necessary modifications could be made. Furthermore, at the end of each lesson, quizzes were held through the Kahoot application, which encouraged a sense of competition among the cooperative learning groups.

By the end of the semester; a jury formed of lecturers from the Computer and Instructional Technologies Teaching Department evaluated the educational game software and students presented their reports.

In the last week of the course, the attitude scale was applied to the teacher candidates as a post-test. Interviews with all the teacher candidates were held in order to determine their opinions about the application.

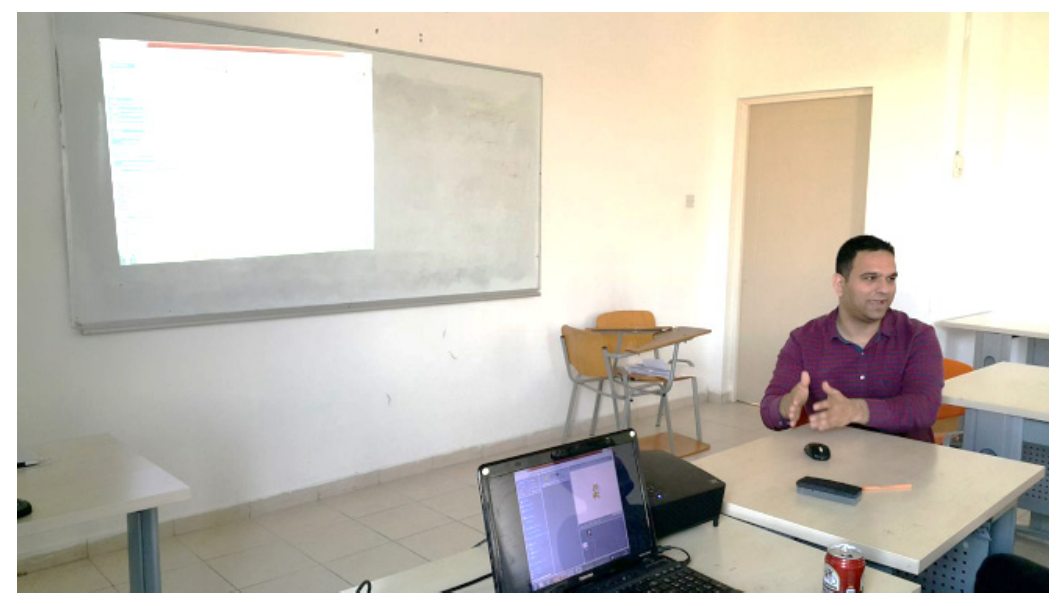

Fig. 2. Meeting with expert

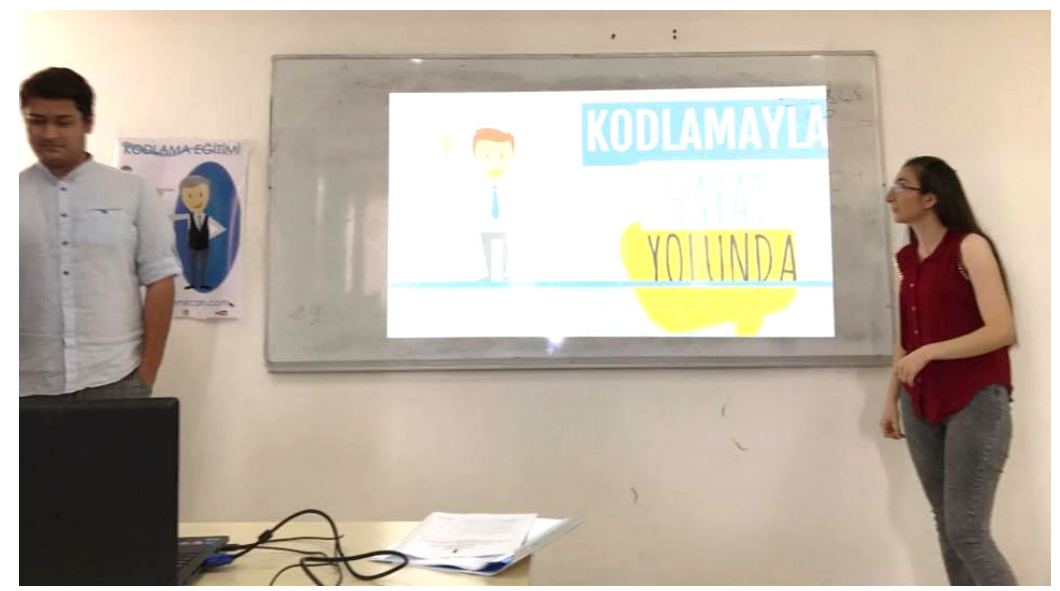

Fig. 3. Introductory videos and posters of educational games that students developed 
Paper-Effects of the Gamification Supported Flipped Classroom Model on the Attitudes and Opinions...

\section{$3 \quad$ Results}

The findings as a result of the qualitative and quantitative data within the scope of the the objectives of the study are explained below.

\subsection{The attitudes of the teacher candidates on educational computerized game-supported Coding Teaching}

Table 1. Attitudes towards coding learning

\begin{tabular}{|c|c|c|c|c|c|c|c|c|}
\hline & & $\mathbf{N}$ & $\bar{X}$ & SS & df & $\mathbf{t}$ & $\mathbf{P}$ & Explanation \\
\hline \multirow{2}{*}{$\begin{array}{l}\text { Eagerness for Cod- } \\
\text { ing Learning }\end{array}$} & Pre-Test & 35 & 2.82 & 0.392 & \multirow{2}{*}{34} & \multirow{2}{*}{42.526} & \multirow{2}{*}{.000} & $\mathrm{P}<0.05$ \\
\hline & Post Test & 35 & 4.02 & 0.797 & & & & Meaningful difference \\
\hline \multirow{2}{*}{$\begin{array}{l}\text { The use of computer } \\
\text { games in education }\end{array}$} & Pre-Test & 35 & 2.83 & 0.384 & \multirow{2}{*}{34} & \multirow{2}{*}{47.418} & \multirow{2}{*}{.000} & $\mathrm{P}<0.05$ \\
\hline & Post Test & 35 & 4.06 & 0.083 & & & & Meaningful difference \\
\hline \multirow{2}{*}{ Unsociability } & Pre-Test & 35 & 2.76 & 0.816 & \multirow{2}{*}{34} & \multirow{2}{*}{20.257} & \multirow{2}{*}{.000} & $\mathrm{P}<0.05$ \\
\hline & Post Test & 35 & 4.21 & 0.753 & & & & Meaningful difference \\
\hline \multirow{2}{*}{ General } & Pre-Test & 35 & 2.91 & 0.413 & 34 & 41.674 & .000 & $\mathrm{P}<0.05$ \\
\hline & Post Test & 35 & 3.79 & 0.666 & & & & Meaningful difference \\
\hline
\end{tabular}

The eagerness of the students to learn coding in the Computer and Instructional Technology Teaching Department was at a medium level before the study $(x=2.82)$, whereas after the study that was held with the gamification supported flipped classroom implementation, the eagerness increased to a high level $(x=4.02)$, which means they became more motivated to learn coding. Before the study the students were indecisive in regard to the statement, "I think that learning to code would be helpful for me"; however, after the study it moved to the "completely agree" level. They were indecisive towards the statement "If I use game coding, I can be more successful in my lessons", while after the study, their opinions changed to "completely agree".

Before the study, the eagerness of the teacher candidate students regarding the use of computer games in coding training was at a medium level $(x=2.83)$ and after the coding training incorporating the activities in the gamification supported flipped classroom, their eagerness increased to a high level $(x=4.06)$. The teacher candidates were still indecisive towards the statement "studying by benefitting from computer games is helpful", which changed the "completely agree" level after the implementation. In regard to the statement, "the antisocial use of computer games in the educational process" the students were indecisive $(x=2.76)$ before the study, whereas after the implementation of the study, the answers changed to "completely disagree" $(x=4.21)$. The average values for the attitudes of the teacher candidates for coding learning before the gamification supported flipped classroom in general were $x=2.91$, whereas it became $\mathrm{x}=3.79$ after the coding learning in gamification supported flipped classroom. According to these findings, it can be stated that the game coding process in the gamification supported flipped classroom had a positive effect on the teacher candidates' attitudes. 


\subsection{The Opinions of Students about Flipped and Gamified Learning}

The findings in relation to the question of "How did you feel at the beginning of the semester when you heard that a different application was going to be used, such as the gamification supported flipped classroom?" are illustrated in Table 2.

Table 2. The initial reactions of teacher candidates towards the application

\begin{tabular}{lc}
\hline Theme & f \\
\hline Excitement & 16 \\
\hline Curiosity & 11 \\
\hline Concern & 5 \\
\hline Uneasiness & 3 \\
\hline
\end{tabular}

The reactions of the teacher candidates can be interpreted as being generally positive. Almost half of the teacher candidates were excited when they heard about the application and their curiosity increased. However, some of the teacher candidates were concerned and felt uneasy as a result of new application that was to be used in the project development course's coding projects. Below are some of the answers given by the teacher candidates.

TC2: "As I have used the gamification applications on Foursquare, etc. I became excited because it was going to be used in our lessons. I was curious about how it would be integrated into the learning process and I waited excitedly. Also, learning the lesson topics at home was exciting because it is a different experience."

TC7: "I got excited as we were going to receive the lessons at home and participate in activities in the classroom and the lessons are boring when they are directly taught in class. Doing in-class activities and being awarded badges made me excited and increased my motivation towards the lessons."

TC13: "When I heard that we would learn lesson topics at home and then go to the class, I was curious about how our teacher would organize the activities in class. Generally, instead of attending the lessons supported by videos, we learnt by watching the video after the lesson. This time, as it would be the reverse, I waited for the lesson with a sense of curiosity and excitement."

TC4: "When I heard that we would learn the topics through videos and other educational materials integrated to the Moodle environment, I had concerns. I was uneasy as to whether I could succeed or not, as there was no teacher or friend at home to whom I could ask questions."

TC11: "We had to study hard even in the traditional lessons and I was uneasy when I heard that we were going to learn at home and go to the class and I had doubts about the chances for success."

According to these findings, the teacher candidates were excited and curious about the gamification supported flipped classroom model and so their motivation as well as their interest increased towards the lessons. However, it can be said that concerns and doubts can also be raised towards these the new approaches that the teacher candidates face. 


\subsection{Student Opinions about Videos in the Application}

The findings in relation to the question of "As computer and instructional technologies are the teachers of the future, how do you evaluate the videos on the environment that is designed for flipped classroom model?" are illustrated in Table 3.

Table 3. Opinions of teacher candidates about educational videos

\begin{tabular}{lc}
\hline Theme & f \\
\hline Deductive & 21 \\
\hline Attractive & 6 \\
\hline Understandable & 5 \\
\hline Insufficient Activities & 2 \\
\hline
\end{tabular}

According to the table above; the students predominantly gave positive opinions when they evaluated the online videos during the game coding training. The majority of teacher candidates stated that the videos were short, understandable, attractive and had deductive content. However, two of the teacher candidates found the number of activities in the videos to be insufficient. Some of the opinions of the teacher candidates are given below.

TC7: "The videos that were uploaded periodically before the lesson were deductive and attractive enough. The targeted topic was emphasized through directions, aims and objectives before watching, which eased the completion of tasks."

TC3: "I can summarize the videos we watched as being simple and short. Making the videos short and removing the unnecessary information facilitated the learning process easier. Also, the screen views shared were more understandable and high quality graphics, which is a good detail."

TC14: "We found and were watching the video links that supported the things we learnt in the lesson. However, the videos we watched in this lesson were prepared professionally and the voice and graphics had high quality that watching them increased our interest in the topic and without distracting our attention. Actually, I have watched videos before in which voice system was so low that I couldn't bear to listen to them, but the voiceover in these videos was really good."

TC9: "In some parts of the video, there were summaries and illustrations in the form of text, which improved the ability to memorialize information Also, as a result of the quizzes we took between videos, I realized that there were some parts that I didn't understand and I had the opportunity to watch it again."

TC6: "I found the number of activities which encouraged us to coding to be insufficient in the videos. All the activities occurred in the classroom, and I believe the number of activities out of the classroom which were based on watching and reading should be increased."

According to the findings, the teacher candidates found the videos that were integrated into the online course designed for the flipped classroom to be sufficient and also the vast majority of teacher candidates found that the videos were deductive. Furthermore, as the videos were short and simple, the students evaluated the videos with illustrations in the texts and quizzes as positive. Furthermore, the voiceover was 
clear and understandable, which was evaluated as positive. Nevertheless, two students found the number of activities in the videos to be insufficient and therefore needed improvement.

\subsection{Student Opinions about Videos in the Application}

While the teacher students were developing games during their learning through the gamification supported flipped classroom model in the Project Development course, they provided their opinions and the related data are illustrated in Table 4.

Table 4. The difficulties that the students faced during the project development period

\begin{tabular}{lc}
\hline Theme & f \\
\hline Lack of Substructure & 10 \\
\hline Shortage of Time & 5 \\
\hline
\end{tabular}

As can be seen in Table 4, the teacher candidates stated that the lack of substructure and shortage of time as the general difficulties they faced during the game development tasks in their projects. Some of the opinions of the teacher candidates are given below:

TC17: "We did our activities and projects in the flipped classroom, which was a new approach during the project development course. Although my opinions towards the application were generally positive, accessing the videos on the online system instead of YouTube took some time as we had to set a password, choose the course, find the related week etc. However, if it was loaded on YouTube, I could easily access it whenever I wanted."

TC19: "The application was really effective, but some of our phones did not have enough software and I had buffering problems while using the application on my phone for the gamification quiz activities. I believe the students need to be supported for the technical substructure for the lessons in this application."

TC4: "The applications implemented during the Project Development course took too much of our time. Sometimes, I had to watch the videos twice. Although we could get support from our teachers and friends for the difficult points, I believe this application takes too much time, as we have to study for our other lessons."

As can be seen from the opinions above, the students did not have different problems, except for some technical difficulties and a lack of time.

\subsection{Teacher candidate opinions about the activities}

The data about the teacher candidates' opinions about in-class activities are given in Table 5.

According to the data in Table 5, in the gamification supported flipped classroom application approach, the teacher candidates evaluated the in-class activities and they stated that the gamification application increased the levels of motivation, competition and entertainment. Furthermore, as the teacher candidates came to the class prepared, they said that during the in-class activities, they could learn the topic through rein- 
Paper-Effects of the Gamification Supported Flipped Classroom Model on the Attitudes and Opinions...

Table 5. Teacher candidate opinions about the activities

\begin{tabular}{lc}
\hline Theme & f \\
\hline Motivation & 23 \\
\hline Entertainment & 19 \\
\hline Competition & 18 \\
\hline
\end{tabular}

forcement which had a positive effect on their learning. Some of the opinions of the students are given below.

TC1: "I believe the flipped education approach is helpful for the students because the topics can be taught prior to the class through videos, followed by application, reinforcement and different activities in each lesson and I think this has a positive effect for each individual."

TC9: "Thanks to the gamification quizzes in the class activities, there is a competitive environment in the classroom and this increases my motivation for achieving higher marks. Furthermore, with the in-class activities, the lesson becomes more entertaining."

TC11: "The cooperative learning activities and quizzes in the classroom increased my motivation. Also, when we are awarded the badges for completing tasks, our motivation increases."

\section{Discussion and Conclusion}

This is an area in which science and technology are now significantly important, which means there is an increase for the need of equipped people who can create and use technology [5]. For this reason, coding training has become essential and there must be applications that support problem-solving. For this reason, this study aimed to determine the effects and opinions of teacher candidates towards coding training through gamification supported flipped classroom applications.

The gamification concept is an educational platform which aims at increasing the internal motivation effects rather than external motivations through the process of rewarding and giving feedback [13]. The interest and motivation of students during their education are important factors in the success of lessons. When the main problems of learners in terms of motivation and lack of interest are considered, through the use of gamified learning environments and flipped classrooms these problems can be resolved.

According to the results of the study, the teacher candidates studying in the gamification supported flipped classroom were found to be more eager to participate in coding training and they demonstrated positive attitudes after the implementation. According to this result, the designed environment had a positive effect on the students' attitudes towards coding. Likewise, in a study aimed at determining the effects of flipped classroom applications, Caliskan and Bicen [4] found that such applications had a positive effect on teacher candidates.

Another result of the study was that the attitudes on the use of computer games in education increased positively after the implementation of the gamification supported 
flipped classroom. In regard to this result, it can be said that the attitudes of teacher candidates towards the use of gamification in and out of the classroom towards the educational aims have increased positively.

In terms of the attitudes towards the anti-social elements computer games for individuals, the teacher candidates stated that provided the games were used for educational purposes and with certain limits it would not create any unsociability for them. In their studies, Dicheva, Agre and Angelova [9] interpreted that the gamified learning process had a positive effect.

The qualitative data of the research were analyzed under four topics in detail, namely "The initial reaction towards the gamification supported flipped classroom approach", "opinions towards videos", "limitations" and "opinions about the activities of gamification supported flipped classrooms". Each topic had its own sub-themes. The research results show that the attitudes of the vast majority of teacher candidates on coding training in the gamification supported flipped classroom were positive.

At the beginning of the study, although there were some students who were uneasy and had doubts about the approach, they gave positive feedback after the study. However, the results about the education videos added to the flipped classroom environment revealed that the students had positive attitudes as the videos were short, summarized and comprehensible and also the addition of animations and quizzes were beneficial and increased the motivation of the teacher candidates. In a similar study conducted by Sengel [25] about teacher candidates, it was found that their motivation had also increased. Love, Hodge, Grandgenett and Swift [18] stated that the deductive videos recorded in the Moodle environment facilitated the learning phases of the learners and activated the classroom time through out of class concepts, which provided the opportunity for problem-based learning and more applicant activities.

Another result of the study is the limitations of the coding process through the gamification supported flipped classroom approach. Some of the teacher candidates expressed that the greatest limitation was due to technical substructure insufficiencies. Since several of the students' phones were not completely equipped, they had difficulties and they could only study using the computers in their houses. Another limitation is that when the students watch the videos, it can significantly decrease their Internet quota. In a study by Edessa [10], it was found that the media richened by the educational materials attracted the students' interests, which increased their motivation.

Finally, the study results show that the vast majority of teacher candidates were satisfied with the activities implemented through the gamification supported flipped classroom as well as the increase in their motivation and in-class competition. Similarly, in a study conducted by Gooch, Vasalou, Benton and Khaled [14], the results revealed that the awarding of badges affected the perceptions of students significantly. Additionally, in his study, Ar [2] mentioned that the students found gamified learning to be entertaining and competitive. Uzunboylu and Karagozlu [28] stated that the learning phase through the flipped classroom model had a positive effect on motivation and interests. Furthermore, Dicheva, Agre and Angelova [9] demonstrated that gamification supported lessons were more interesting, motivating and the student success in their lessons increased. In this regard, all future teacher candidates should consider having at least a smartphone, tablet or computers and a high quality Internet 
Paper-Effects of the Gamification Supported Flipped Classroom Model on the Attitudes and Opinions...

connection. Moreover, not only inside the classroom, but also throughout the campus. a free Wi-Fi connection must be provided.

\section{Acknowledgement}

This work was supported by Research Fund of the Near East University. Project Number: SOS-2016-2-001

\section{References}

[1] Akdemir, O., Bicer, D., \& Parmaksiz, R. (2015). Prospective teachers' information and communication technology metaphors. World Journal on Educational Technology: Current Issues, 7(1), 09-21. https://doi.org/10.18844/wjet.v7i1.19

[2] Ar, N. A. (2016). The effects of gamification on academic achievement and learning strategies usage of vocational high school students. Master Thesis, Sakarya University, Institute of Educational Sciences, Sakarya, Turkey.

[3] Birinci, C., \& Karagözlü, D. (2016). Determination of teacher candidates' anxiety levels on using Facebook for instructional purposes. World Journal on Educational Technology: Current Issues, 8(1), 41-50. https://doi.org/10.18844/wjet.v8i1.500

[4] Caliskan, S., \& Bicen, H. (2016). Ters Yüz Edilmiş Öğrenme Ortamlarının Öğrenci Başarısına ve Uygulamaya Yönelik Etkisi. Master Thesis, Near East University, Institute of Educational Sciences, North Cyprus.

[5] CNNTurk (2017). Kodlama eğitimi ve gelecek için önemi. Retrieved 20 August 2017 from: https://www.cnnturk.com/teknoloji/kodlama-egitimi-ve-gelecek-icin-onemi

[6] Curzon, P. (2015). Computational Thinking: Searching to Speak. Accessed November 17, 2016. https://cs4fndownloads.files.wordpress.com/2016/02/searchingtospeak-booklet.pdf

[7] Dadakhodjaeva, K. (2017). Good Behavior Game: Effects On and Maintenance of Behavior in Middle-School Classrooms Using Class Dojo. Dissertations, 363. Retrieved 20 June 2017 from:

[8] Demiralay, Ö.G.R., \& Karataş, S. (2014). Flipped Classroom Model. Journal of Research in Education and Teaching, 3(3), 333-340.

[9] Dicheva, D., Dichev, C., Agre, G. \& Angelova, G. (2015). Gamification in Education : A systematic mapping study gamification in education : A systematic mapping study. Educational Technology ve Society, 18(June), 75-88.

[10] Edessa, S. (2017). Impacts of insufficient instructional materials on teaching biology: Higher education systems in focus. Cypriot Journal Of Educational Sciences, 12(1), 02-08. https://doi.org/10.18844/cjes.v12i1.267

[11] Efe, M. D. (2014). Situation of adults who have been working on e-learning field on the usage of mobile device applications with the aim of professional learning. Master Thesis, Gazi University, Institute of Educational Sciences, Ankara, Turkey

[12] Erkan, E., \& Altun, H. (2003). Java ve WEB tabanlı uzaktan eğitim: e-eğitim için sanal sınıf ve sanal laboratuvar projesi. Elektrik, Elektronik, Bilgisayar Mühendislikleri Eğitimi, 1.

[13] Gökkaya, Z. (2014). A New Approach of Adult Education: Dramatization. Hasan Ali Yücel Eğitim Fakültesi Dergisi, 21(11-1), 71-84.

[14] Gooch, D., Vasalou, A., Benton, L. \& Khaled, R. (2016). Using gamification to motivate students with dyslexia. Proceedings of the 2016 CHI conference on human factors in com- 
Paper-Effects of the Gamification Supported Flipped Classroom Model on the Attitudes and Opinions...

puting systems - CHI '16 (ss. 969-980), England. https://doi.org/10.1145/2858036.28 $\underline{58231}$

[15] Günüç, S., Odabaşı, H.F. \& Kuzu, A., (2013). The Defining Characteristics of Students of the 21st Century by Student Teachers: A Twitter Activity. Journal of Theory and Practice in Education, 9(4), 436-455

[16] Kanbul, S., \& Uzunboylu, H. (2017). Importance of Coding Education and Robotic Applications for Achieving 21st-Century Skills in North Cyprus. International Journal of Emerging Technologies in Learning, 12 (1) 130-140. https://doi.org/10.3991/ijet. v12i01.6097

[17] Keçeci, G., Alan, B., \& Zengin, F. K. (2016). Educational Computer Games Assisted Learning Coding Attitude Scale: Validity and Reliability Study. Education Sciences, 11(4), 184-194. https://doi.org/10.12739/NWSA.2016.11.3.1C0661

[18] Love, G., Hodge, A., Grandgenett, N., \& Swift, A. W. (2014). Student learning and perceptions in a flipped linear algebra course. International Journal of Mathematical Education in Science and Technology, 45(3), 317-324. https://doi.org/10.1080/0020739X.20 13.822582

[19] Maloney, J., Resnick, M., Rusk, N., Silverman, B., \& Eastmond, E. (2010). The scratch programming language and environment. ACM Trans. Computer Education 10 (4), 16. https://doi.org/10.1145/1868358.1868363

[20] Marczewski, A. (2013). Gamification: a simple introduction. Andrzej Marczewski.

[21] Muijs, D. (2004). Doing quantitative research in education with SPSS. London: Sage Publications. https://doi.org/10.4135/9781849209014

[22] Prensky, M. (2001). Digital natives, digital immigrants. MCB University Press, 9(5), 1-16.

[23] Roach, T. (2014). Student perceptions toward flipped learning: New methods to increase interaction and active learning in economics. International Review of Economics Education, 17, 74-84. https://doi.org/10.1016/j.iree.2014.08.003

[24] Sarıtaş, M. \& Yıldız, Ö. (2015). Eğitimde oyunlaştırma ve Ters-Yüz sınıflar. Akademik Bilişim Dergisi, 4- 6 Şubat 2015, Anadolu Üniversitesi, Eskişehir

[25] Sengel, E. (2016). To FLIP or not to FLIP: Comparative case study in higher education in Turkey. Computers in Human Behaviour. 64 (2016) 547-555 https://doi.org/10.1016/j.chb. 2016.07.034

[26] Simpson, V., \& Richards, E. (2015). Flipping the classroom to teach population health: increasing the relevance. Nurse Education in Practice, 15(3), 162- 167. https://doi.org/10.1016/j.nepr.2014.12.001

[27] Tugun, V. (2016). Validity and Reliability Dissertation of the Scale Used for Determination of Perceptions and Attitudes of Teacher's Proficiency in Tablet PC-Supported Education. Cypriot Journal of Educational Sciences, 11(2), 51-57. https://doi.org/10.18844/cjes. v11i2.617

[28] Uzunboylu, H. \& Karagozlu, D. (2017). The Emerging Trend of the Flipped Classroom: A Content Analysis of Published Articles between 2010 and 2015. RED. Revista de Educación a Distancia. 54 (4). DOI: https://doi.org/10.6018/red/54/4

[29] Uzunboylu, H., Hursen, C., Özütürk, G., \& Demirok, M. (2015). Determination of Students' Attitudes for Mobile Integrated EFL Classrooms in Higher Education Institutions and Scale Development. Journal of Universal Computer Science, 21(10), 1283-1296.

[30] Yesil, D. (2014). Eğitsel video ve sunum hazırlamak için ipuçları. Retrieved on 12 July 2017 from: https://didemyesil.com/2014/10/29/egitsel-video-ve-sunum-hazirlamak-icin-ip uclari/ 


\section{$7 \quad$ Authors}

Hasan Huseyin Özer is with the Department of Computer Education \& Instructional Technology, Near East University, P.O. Box: 99138, Nicosia, North Cyprus (email: hasanhuseyin.ozer@neu.edu.tr).

Sezer Kanbul is with the Department of Computer Education \& Instructional Technology, Near East University, P.O. Box: 99138, Nicosia, North Cyprus (e-mail: sezer.kanbul@neu.edu.tr).

Fezile Özdamlı is with the Department of Computer Education \& Instructional Technology, Near East University, P.O. Box: 99138, Nicosia, North Cyprus (e-mail: fezile.ozdamli@neu.edu.tr).

Article submitted 31 August 2017. Published as resubmitted by the authors 23 October 2017. 